\title{
A study of $\mathrm{Ca}^{2+}$-heparin complex-formation by polarimetry
}

\author{
David GRANT, William F. LONG, ${ }^{*}$ Colin F. MOFFAT and Frank B. WILLIAMSON \\ Polysaccharide Research Group, Department of Molecular and Cell Biology, University of Aberdeen, Marischal College, \\ Aberdeen AB9 1AS, Scotland, U.K.
}

\begin{abstract}
Possible inflexions in isothermal binding plots derived from equilibrium-dialysis measurements and in equivalent plots obtained by polarimetric measurements accord with the possibility that discrete $\mathrm{Ca}^{2+}$-heparin-water complexes/phases may exist, the nature and proportions of which depend on the conditions under which the interaction occurs. Analysis of the plots obtained by polarimetric study of chemically modified heparins suggests, for individual substituents groups, an order of importance of carboxylate $>N$-sulphonate $>N$-acetyl $>O$-sulphate for the $\mathrm{Ca}^{2+}$-heparin interaction occurring at $\left[\mathrm{Ca}^{2+}\right] /[$ heparin disaccharide] ratios of less than 0.5 . At higher ratios, transitions occur that eventually lead to the formation of a complex in which the stoichiometry of association is $1 \mathrm{Ca}^{2+}$ ion/heparin disaccharide unit.
\end{abstract}

\section{INTRODUCTION}

Heparins are strongly acidic and possess several chemical groups that interact with a variety of cations. Many modulations by metal ions, including $\mathrm{Ca}^{2+}$, of the activities of heparins in vivo and in vitro have been discussed (e.g. Long \& Williamson, 1979, 1982). Results of heparin-cation studies carried out with dilute aqueous solutions have been interpreted either in terms of simple electrostatic interactions or in terms of additional chemical interactions resulting in cations binding to specific sites on the polymer. Manning $(1969 a, b, c)$ predicted that counter-cation condensation on to a polyanion occurred whenever a critical density of charge along the polymer was exceeded, and suggested the existence of a critical counterion concentration, below which condensation occurred, and above which the ions existed in an ion atmosphere. An additional, 'two-variable' model (Manning, 1977, 1978) extended the idea to include the possibility of exchange of cations between sites. In these models, ion interaction is independent of the chemical nature of the anionic sites on the polyelectrolyte, and, except for its charge, is independent of the chemical nature of the counterion.

Physical studies by Boyd et al. (1980), Liang \& Chakrabarti (1982) and Mattai \& Kwak (1988), however, support the concept of site-specific $\mathrm{Ca}^{2+}$-heparin interaction. I.r. spectra of different cation-heparin complexes showed cation-dependent variation and a cation-dependent transition between conformational states, possibly with different hydration chemistries (Grant et al., $1987 a, b)$. Further, a dependence on $\left[\mathrm{Na}^{+}\right]$of the diffusion rates of ions in aqueous heparin solutions lacking additional electrolyte (Ander \& Lubas, 1981; Ander \& Kardan, 1984), and an apparent polyanionic charge on heparin smaller than that predicted by electrostatic theory (Tivant $e t$ al., 1983), suggest that all heparincation interactions may not be explained by simple electrostatics. These studies are well summarized by Nieduszynski (1989).

For $\mathrm{Ca}^{2+}$ binding, a predominant role for carboxylate groups has been suggested (Grant et al., 1987a), with $N$-sulphonate groups playing a subsidiary role (Liang \& Chakrabarti, 1982; Ayotte \& Perlin, 1986). In addition, in the presence of $\mathrm{Ca}^{2+}$ the polymer may be held in a conformation that is stabilized by an interaction between $N$-sulphonate and carboxylate groups, possibly involving hydrogen-bonding (Grant et al., 1987a,b). Additional complications involve the possibility of multiphasic interactions (Burger et al., 1984; Grant et al., 1986), and the involvement of co-ordinated water molecules in the interaction (Grant et al., 1987a).
The present paper explores $\mathrm{Ca}^{2+}$-heparin interaction with the use of equilibrium dialysis, polarimetry and i.r. spectroscopy; the results obtained accord with the notion that more than one type of $\mathrm{Ca}^{2+}-$ heparin complex may exist.

\section{EXPERIMENTAL}

The source, preparation and properties of the heparin and of the chemically modified heparins used have been described previously (Grant et al., 1987a, 1989). Polymers were converted into particular cation complexes by passage through appropriate cation forms of Amberlite IR-120 cation-exchange resin. Sparksource m.s. showed a greater than $99 \%$ efficiency of the cationexchange process. Water contents of $\mathrm{Na}^{+}$forms of heparin and of modified heparins were deduced following calculation of formula weights from uronic acid residue (Blumenkrantz \& Asboe-Hansen, 1973) or, for carboxy-reduced heparin, glucosamine residue (Hurst \& Settine, 1981) assay. An average heparin disaccharide unit was taken to be hexadecahydrated (Atkins et al., 1974; Grant et al., 1990) tetrasodium 2-O-sulphatoiduronosyl 6-O-sulphatoglucosamine $2-N$-sulphamate.

Details of equilibrium dialysis were as described by Grant et al. (1986) and Woodhead et al. (1986). I.r. spectroscopy of aqueous films of heparin-cation complexes was carried out by a multiple-specular-reflectance technique as described by Grant et al. $(1987 a)$.

Polarimetric measurements were made with a Thorn Automation-NPL type 243 automatic polarimeter. Nitrocellulose membrane $(2 \mu \mathrm{m})$-filtered solutions of heparin or of modified heparins $(6 \mathrm{ml}$ in water, except for the experiment reported in Fig. 1, in which the solvent was $0.15 \mathrm{M}-\mathrm{NaCl}$ ) were prepared and placed in the silanized glass cell immediately before the experiment. Consecutive $1 \mu$ additions of $\mathrm{CaCl}_{2}$ solution (2.02 M) were made to the cell. Correlations were applied for the cell blank and for the small dilution effects resulting from $\mathrm{CaCl}_{2}$ addition. Addition of $\mathrm{CaCl}_{2}$ solution, which itself was not optically active, elicited an increase in optical rotation that reached a maximum at high $\left[\mathrm{Ca}^{2+}\right]$ (Moffat et al., 1984). Similar experiments were carried out with solutions of $\mathrm{LiCl}, \mathrm{NaCl}$, $\mathrm{CuCl}_{2}$ and $\mathrm{ZnCl}_{2}$. Additions of each of these to the polymer solution elicited an increase in polymer optical rotation; in the case of $\mathrm{CuCl}_{2}$ solution, addition produced a decrease in optical rotation. Addition of $\mathrm{CaCl}_{2}$ solution to modified heparins produced an increase in polymer optical rotation, except for de$\mathrm{N}$-sulphonated de- $\mathrm{O}$-sulphated $\mathrm{N}$-acetylated heparin, in which

\footnotetext{
* To whom correspondence should be addressed.
} 
case a decrease in optical rotation occurred. For the purpose of comparing results from polarimetric measurements with those obtained from equilibrium dialysis experiments, the change in optical rotation that occurred after addition of cation was expressed as [(optical rotation in the presence of cation) - (optical rotation in the absence of cation)]/[(maximal optical rotation at high cation concentration)-(optical rotation in the absence of cation)]. At 'high' cation concentration, the [cation]/[heparin disaccharide] ratio was 6 ; at this ratio, no further detectable increase in the corrected optical rotation value occurred on addition of more cation. Optical rotations were recorded with light of $546 \mathrm{~nm}$ wavelength in a pathlength of $0.61 \mathrm{dm}$, at a temperature of $25^{\circ} \mathrm{C}$, and at a polymer concentration that, if not indicated otherwise in Fig. 3, was $0.477 \mathrm{~g} / 100 \mathrm{ml}$ in water. Because the different degrees of hydration of heparin and modified heparins (Table 1) contribute to polymer mass, but are unlikely to contribute directly to polymer optical activity, experimentally recorded optical rotations are reported directly, rather than as specific rotations.

\section{RESULTS AND DISCUSSION}

Fig. 1 ( $\bigcirc$ symbols) shows the isothermal saturation fractions of potential binding sites on heparin occupied by $\mathrm{Ca}^{2+}$ as a function of [total $\mathrm{Ca}^{2+}$ ], when a binding site is taken to be an average heparin disaccharide unit. The results are from an equilibrium-dialysis experiment. The symbols in Fig. 1 show an equivalent plot derived from optical-rotation changes observed under equivalent conditions of [heparin] and $[\mathrm{NaCl}]$. Fig. 2 shows a plot of the maximal increase or decrease in optical rotation (obtained when high [cation] was added to solutions of $\mathrm{Na}^{+}$-heparin), against independently derived association constants for heparin-cation interactions. The relationship apparent in Fig. 2, together with the near-identity of the plots in Fig. 1, suggest that optical-rotation measurements offer an indirect but

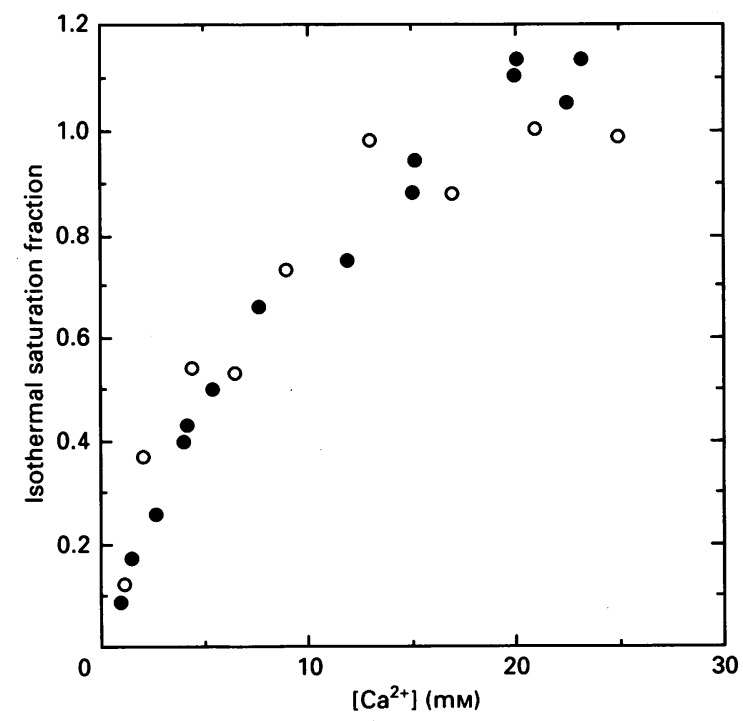

Fig. 1. Isothermal saturation fractions of binding sites on heparin occupied by $\mathrm{Ca}^{2+}$, and equivalent fractions derived from polarimetric measurements, as functions of [total $\left.\mathrm{Ca}^{2+}\right]$

A binding site was taken to be an average heparin disaccharide unit (see the Experimental section). Isothermal saturation fractions obtained by equilibrium dialysis; $O$, equivalent fractions derived from polarimetric measurements as described in the Experimental section. In both experiments [heparin disaccharide unit] was $0.005 \mathrm{M}$ and $[\mathrm{NaCl}]$ was $0.15 \mathrm{M}$.

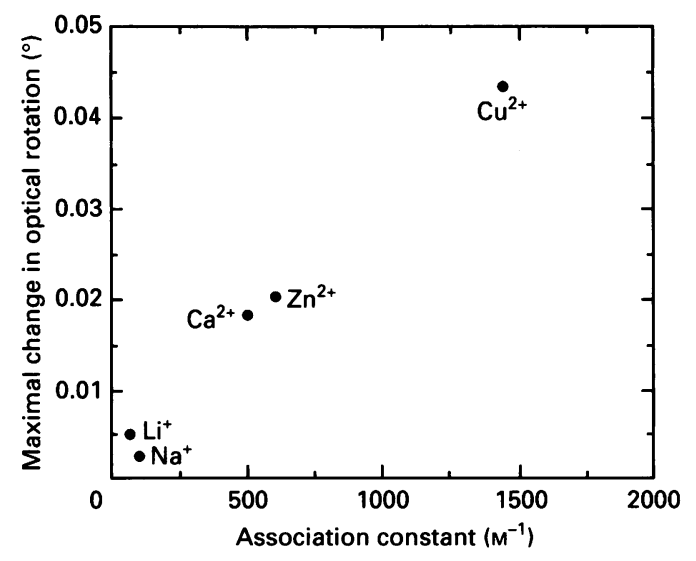

Fig. 2. Maximal alterations in optical rotation seen on addition of cations to $\mathrm{Na}^{+}$-heparin as functions of independently derived cation-heparin association constants

Heparin association constants were from the following sources: Herwats et al. (1977), $\mathrm{Li}^{+}, \mathrm{Na}^{+}, \mathrm{Cu}^{2+}$; Mattai \& Kwak (1981), $\mathrm{Ca}^{2+}$; Woodhead et al. (1986), $\mathrm{Zn}^{2+}$. In each case optical rotations were measured at a [cation]/[heparin disaccharide unit] ratio of 6 .

simple, fast and non-destructive method of exploring heparincation association. For example, from the plot in Fig. 2, tentative association constants for the interaction of $\mathrm{Mg}^{2+}, \mathrm{K}^{+}, \mathrm{Fe}^{2+}$ and $\mathrm{Ba}^{2+}$ with heparin under these conditions may be estimated to be approx. 25, 75, 555 and $600 \mathrm{M}^{-1}$ respectively. These values accord with previous estimates, where they are available, of the affinities of these cations for heparin (Dunstone, 1962).

Fig. 3 shows polarimetry-derived plots for $\mathrm{Ca}^{2+}$-heparin interaction obtained with various concentrations of heparin in water rather than, as in Fig. 1, salt solution. They suggest that, under these conditions, optical-rotation changes approach completion at a $\left[\mathrm{Ca}^{2+}\right] /[$ heparin disaccharide] ratio of about 1 . Inflexions in similar plots derived from equilibrium-dialysis experiments have been interpreted in terms of a multiphasic interaction between cation and polymer (Boyd et al., 1980; Grant et al., 1986; Woodhead et al., 1986). Future polarimetric measurement, with even more precisely structurally defined polymer preparations than are used here, offers the possibility of more detailed analysis of putative points of inflexion than has been undertaken following equilibrium-dialysis experiments, in which the limited number of samples taken can restrict the precision of the plots constructed. However, the present results suggest that an inflexion may occur at a ratio of about 0.5 ; certainly at lesser ratios a direct linear relationship appears to exist between the polarimetry-derived fraction and the $\left[\mathrm{Ca}^{2+}\right] /$ [heparin disaccharide] ratio. This indicates that, under such conditions, cation-heparin interaction occurs by a mechanism that cannot be described adequately in terms of conventional solution-phase reversible-equilibrium thermodynamics. This is also suggested by the coincidence of the plots obtained with different heparin concentrations (Fig. 3).

Because of the relationship suggested by the results in Fig. 2, polarimetry-derived plots for the interaction of $\mathrm{Ca}^{2+}$ with several modified heparins were prepared, in an attempt to assess the importance of various heparin substituent groups to $\mathrm{Ca}^{2+}$ binding. Table 1 shows maximal optical-rotation changes seen when high $\left[\mathrm{Ca}^{2+}\right]$ was added to solutions of $\mathrm{Na}^{+}$forms of the polymers. The results suggest that each of the modifications decreases the water component of the $\mathrm{Na}^{+}$-polymer complex. Fig. 4, in which the change in optical rotation on addition of high $\left[\mathrm{Ca}^{2+}\right]$ is plotted against the water component of the polymers, indicates that the magnitude of the change may depend on the number of 


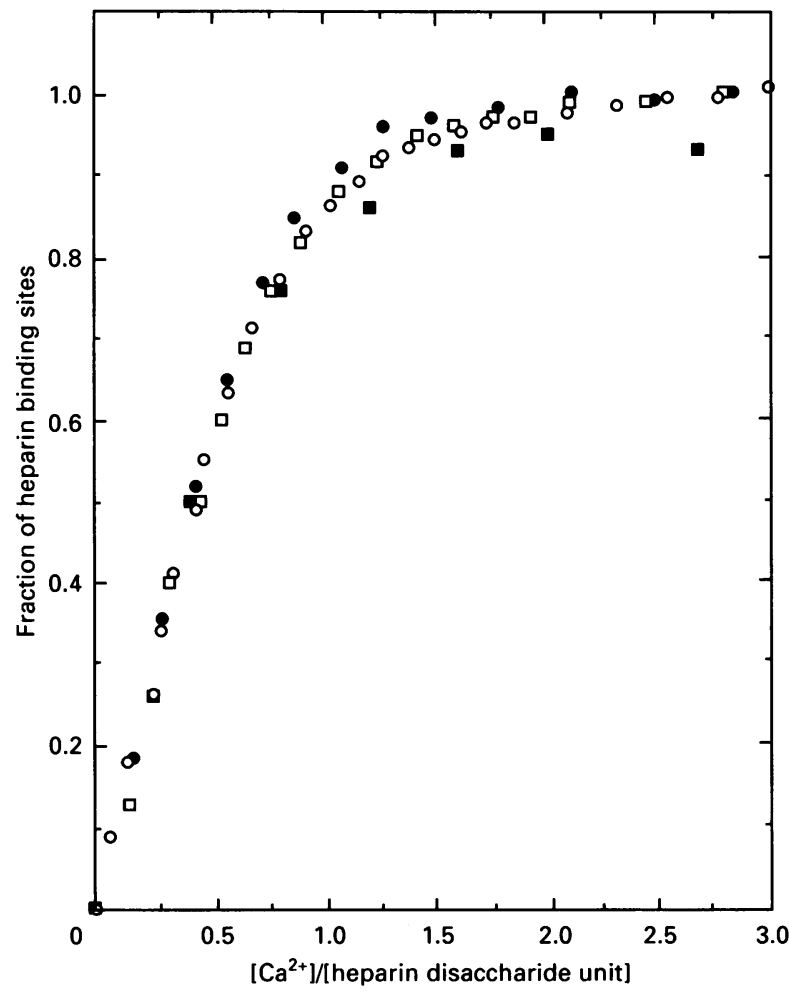

Fig. 3. Polarimetry-derived fraction of binding sites on heparin occupied by $\mathrm{Ca}^{2+}$ as a function of $\left[\mathrm{Ca}^{2+}\right] /$ [heparin disaccharide unit]

A binding site was taken to be an average heparin disaccharide unit (see the Experimental section). Fractions were derived from polarimetric measurements as described in the Experimental section. $\mathrm{Na}^{+}$-heparin concentrations $(\mathrm{mg} / \mathrm{ml})$ in water were: $\boldsymbol{\square}, 2.38 ; \bigcirc$, $4.77 ; \square, 9.56 ; 0,14.30$

water molecules available for release from the polymer on cation binding. Table 1 also shows that, in each case, modification decreases the extent of the optical-rotation change seen in the presence of high $\left[\mathrm{Ca}^{2+}\right]$, suggesting a lowering of the affinity of the polymer for $\mathrm{Ca}^{2+}$. The $\left[\mathrm{Ca}^{2+}\right] /[$ polymer disaccharide] ratios at

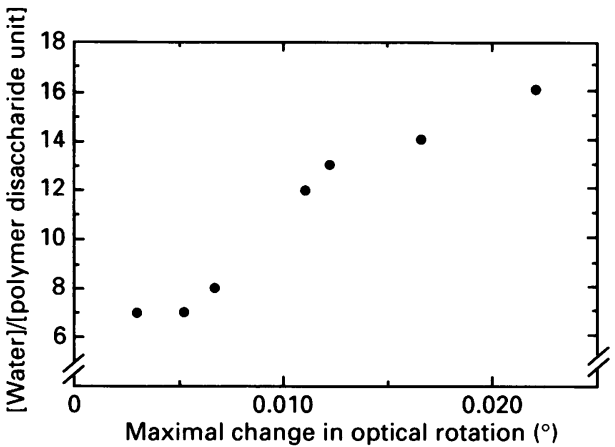

Fig. 4. Maximal optical-rotation changes occurring on addition of $\mathrm{Ca}^{2+}$ to $\mathrm{Na}^{+}$forms of modified heparins as a function of polymer hydration

Data from which the graph is constructed are given in Table 1.

which a linear to non-linear transition occurred in the plots for unmodified, de- $N$-sulphonated, de- $N$-sulphonated $N$-acetylated, de- $N$-sulphonated de-O $O$-sulphated, de- $N$-sulphonated de- $O$ sulphated $N$-acetylated, de- $N$-sulphonated de- $O$-sulphated re- $N$ sulphonated and carboxy-reduced heparins were 0.46 (at a fraction of 0.54 ), 0.28 (at a fraction of 0.58 ), 0.33 (at a fraction of 0.62 ), 0.15 (at a fraction of 0.22 ), 0.33 (at a fraction of 0.59 ), 0.40 (at a fraction of 0.74 ) and 0.22 (at a fraction of 0.25 ) respectively. This suggests that the particular polymer- $\mathrm{Ca}^{2+}$ complex/phase, formation of which is implied by the existence of the linear portion of the polarimetry-derived plots, is stable only at $\left[\mathrm{Ca}^{2+}\right] /[$ polymer disaccharide] ratios that are lower for the modified heparins than for the unmodified polymer, and that, at higher ratios, destabilization of the complex/phase, to generate the non-linear portion of the plot, occurs. By using the above values, it is possible to derive the approximate empirical relationship: $\left[\mathrm{Ca}^{2+}\right] /[$ polymer disaccharide] at the transition point $=(0.20 \times$ carboxylate groups $/$ disaccharide $)+(0.18 \times N-$ sulphonate groups/disaccharide $)+(0.08 \times N$-acetyl groups/ disaccharide $)+(0.06 \times O$-sulphate groups/disaccharide $)$. This suggests the greater importance of the carboxylate and $N$ sulphonate groups and lesser importance of the $\mathrm{N}$-acetyl and $\mathrm{O}$ sulphate groups in the heparin- $\mathrm{Ca}^{2+}$ interaction indicated by the linear portion of the polarimetry-derived plots.

Table 1. Maximal optical-rotation changes occurring on addition of $\mathrm{Ca}^{2+}$ to $\mathrm{Na}^{+}$forms of modified heparins

Optical rotations were measured at $546 \mathrm{~nm}$ as described in the Experimental section. ' $\mathrm{High}$ ' $\left[\mathrm{Ca}^{2+}\right]$ refers to a $\left[\mathrm{Ca}^{2+}\right] /[$ polymer disaccharide] ratio of 6.

\begin{tabular}{|c|c|c|c|c|}
\hline \multirow[b]{2}{*}{ Polymer } & \multirow[b]{2}{*}{$\begin{array}{c}\text { Water } \\
\text { molecules/ } \\
\text { disaccharide }\end{array}$} & \multicolumn{3}{|c|}{ Optical rotation $\left({ }^{\circ}\right)$} \\
\hline & & $\begin{array}{l}\text { In the absence } \\
\text { of } \mathrm{Ca}^{2+}\end{array}$ & $\begin{array}{c}\text { In the presence } \\
\text { of high } \\
{\left[\mathrm{Ca}^{2+}\right]}\end{array}$ & Change \\
\hline Unmodified & 16 & 0.1548 & 0.1769 & 0.0221 \\
\hline Carboxy-reduced & 14 & 0.1682 & 0.1848 & 0.0166 \\
\hline $\begin{array}{l}\text { De- } N \text {-sulphonated, } \\
N \text {-acetylated }\end{array}$ & 13 & 0.1683 & 0.1805 & 0.0122 \\
\hline $\begin{array}{l}\text { De- } N \text {-sulphonated, } \\
\text { de- } O \text {-sulphated, } \\
\text { re- } N \text {-sulphonated }\end{array}$ & 12 & 0.2441 & 0.2551 & 0.0110 \\
\hline De- $N$-sulphonated & 8 & 0.2048 & 0.2115 & 0.0067 \\
\hline $\begin{array}{l}\text { De- } N \text {-sulphonated, } \\
\text { de- } O \text {-sulphated }\end{array}$ & 7 & 0.2490 & 0.2542 & 0.0052 \\
\hline $\begin{array}{l}\text { De- } N \text {-sulphonated, } \\
\text { de- } O \text {-sulphated, }\end{array}$ & 7 & 0.2760 & 0.2730 & 0.0030 \\
\hline
\end{tabular}




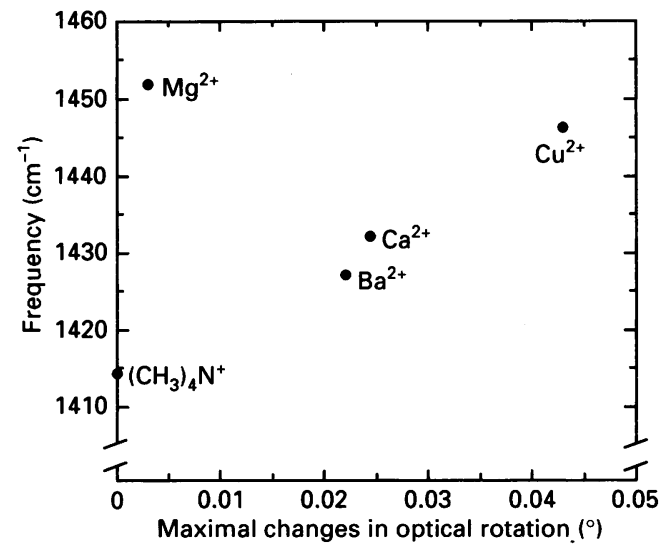

Fig. 5. Frequency of the cation-heparin carboxylate symmetric stretchingbond absorbance as a function of the maximal alteration in heparin optical rotation on cation addition

Optical rotations were measured at a [cation]/[heparin disaccharide unit] ratio of 6.

Conversion of $\mathrm{Na}^{+}$-heparin into $\mathrm{Ca}^{2+}$-heparin results in a shift in the frequency at which the heparin carboxylate symmetric stretching bond absorbs (Grant et al., 1987a), and an increase in $N$-sulphonate absorbance at $1185 \mathrm{~cm}^{-1}$ (Grant et al., 1987b). This suggests involvement of these anionic groups in cation binding. There is little effect on $O$-sulphate group absorbance (Grant et al., 1987a). The conversion of $\mathrm{Na}^{+}-$heparin into $\mathrm{Ca}^{2+}$-heparin is accompanied by a decrease in polymer water content (Grant et al., 1990). A near-i.r. spectroscopic analysis of $\mathrm{Ca}^{2+}$-heparin suggests that, in this form of the polymer, water is held by simple relatively low-energy hydrogen-bonding, whereas in $\mathrm{Na}^{+}$-heparin water is held by stronger hydrogen bonds (Grant et al., 1987a).

Because of the relationship suggested in Fig. 2, and because of the apparent involvement of carboxylate groups in cation binding, the frequency at which the carboxylate band occurred for various bivalent cation-heparin complexes was plotted against the maximal change in optical rotation seen when high [cation] was added to heparin (Fig. 5). The graph includes a plot of the frequency measured in the presence of tetramethylammonium ion, which binds minimally to heparin (Dais et al., 1988). For four cations, an apparently linear relationship suggested by the plot accords with the idea of the importance of the carboxylate group in heparin-cation binding. The $\mathrm{Mg}^{2+}-$ heparin complex generates a point that diverges from the main part of the graph. This result accords with the report that the 'two-variable' version of the ion electrostatic condensation model (Manning, 1977, 1978) accounts adequately for $\mathrm{Mg}^{2+}$-heparin binding, but that other multidentate cations, including $\mathrm{Ca}^{2+}$, bind to heparin more strongly than predicted by the electrostatic model (Mattai \& Kwak, 1981, 1988). The behaviour of $\mathrm{Mg}^{2+}$ in this context presumably results from the chemically 'hard' nature and particular ionic radius of the $\mathbf{M g}^{2+}$ ion, which restricts its octahedral co-ordination to six poorly exchangeable water molecules of hydration.

In summary, our results suggest that the association between $\mathrm{Ca}^{2+}$ and heparin cannot be described adequately in terms of simple electrostatic interactions. We believe that, in an aqueous environment, some heparin-cation complexes may resemble hydrated mineral-like colloidal states that are not subject to simple aqueous solution equilibrium processes and that are maintained by forces additional to simple electrostatic ones. Possible inflexions in isothermal binding plots obtained by equilibrium dialysis and in equivalent plots obtained by polarimetric measurements accord with the suggestion (Boyd et al., 1980; Burger et al., 1984; Grant et al., 1986) that multiple discrete $\mathrm{Ca}^{2+}$-heparin complexes/phases may form, the nature and proportions of which depend on the conditions in which the interaction occurs. The present results suggest that when $\mathrm{Ca}^{2+}$ is added to $\mathrm{Na}^{+}$-heparin solution $\mathrm{Ca}^{2+}$-heparin complexes are formed with an initial stoichiometry of $1 \mathrm{Ca}^{2+}$ ion/heparin tetrasaccharide unit. Once all of the heparin has been converted into this form, then further $\mathrm{Ca}^{2+}$ addition results in $\mathrm{Ca}^{2+}$ binding to form a complex with a stoichiometry of $1 \mathrm{Ca}^{2+}$ ion/ disaccharide unit. It is possible that further experimentation may reveal the existence of discrete $\mathrm{Ca}^{2+}$-heparin complexes having stoichiometries intermediate between 0.5 and $1 \mathrm{Ca}^{2+}$ ion/ disaccharide unit.

We thank Dr. N. E. Woodhead for carrying out the equilibrium dialysis. C. F. M. was supported by a University of Aberdeen Medical Endowments Studentship.

\section{REFERENCES}

Ander, P. \& Kardan, M. (1984) Macromolecules 17, 2431-2436

Ander, P. \& Lubas, W. (1981) Macromolecules 14, 1058-1061

Atkins, E. D. T., Isaac, D. H., Nieduszynski, I. A., Phelps, C. F. \& Sheehan, J. K. (1974) Polymer 15, 263-271

Ayotte, L. \& Perlin, A. S. (1986) Carbohydr. Res. 145, 267-277

Blumenkrantz, N. \& Asboe-Hansen, G. (1973) Anal. Biochem. 54, 484-489

Boyd, J., Williamson, F. B. \& Gettins, P. (1980) J. Mol. Biol. 137, $175-190$

Burger, K., Gaizer, M., Pekli, M., Takacsi Nagy, G. \& Siemroth, J. (1984) Inorg. Chim. Acta 92, 173-176

Dais, P., Holme, K. R. \& Perlin, A. S. (1988) Can. J. Chem. 66, 2601-2604

Dunstone, J. R. (1962) Biochem. J. 85, 336-351

Grant, D., Long, W. F., Williamson, F. B. \& Woodhead, N. E. (1986)

IRCS Med. Sci. Libr. Compend. 14, 805-806

Grant, D., Long, W. F. \& Williamson, F. B. (1987a) Biochem. J. 244, 143-149

Grant, D., Long, W. F. \& Williamson, F. B. (1987b) Med. Hypoth. 24, 131-136

Grant, D., Long, W. F., Moffat, C. F. \& Williamson, F. B. (1989) Biochem. J. 261, 1035-1038

Grant, D., Long, W. F. \& Williamson, F. B. (1990) Biochem. Soc. Trans. 18, 1293-1294

Herwats, L., Laszlo, P. \& Genaard, P. (1977) Nouv. J. Chim. 1, 173-177 Hurst, R. E. \& Settine, J. M. (1981) Anal. Biochem. 115, 88-92

Liang, J. N. \& Chakrabarti, B. (1982) Carbohydr. Res. 106, 101-109

Long, W. F. \& Williamson, F. B. (1979) IRCS Med. Sci. Libr. Compend. $7,429-434$

Long, W. F. \& Williamson, F. B. (1982) Biochem. Biophys. Res. Commun. 104, 363-368

Manning, G. S. (1969a) J. Chem. Phys. 51, 924-933

Manning, G. S. $(1969 b)$ J. Chem. Phys. 51, 934-938

Manning, G. S. (1969c) J. Chem. Phys. 51, 3249-3252

Manning, G. S. (1977) Biophys. Chem. 81, 1829-1833

Manning, G. S. (1978) Q. Rev. Biophys. 11, 179-246

Mattai, J. \& Kwak, J. C. T. (1981) Biochim. Biophys. Acta 677, 303-312

Mattai, J. \& Kwak, J. C. T. (1988) Biophys. Chem. 31, 295-299

Moffat, C. F., Grant, D., Long, W. F. \& Williamson, F. B. (1984) Biochem. Soc. Trans. 12, 301

Nieduszynski, I. (1989) in Heparin: Chemical and Biological Properties, Clinical Applications (Lane, D. A. \& Lindahl, U., eds.), pp. 51-63, Edward Arnold, London, Melbourne and Auckland

Tivant, P., Turq, P., Drifford, M., Madelenat, H. \& Menez, R. (1983) Biopolymers 22, 643-662

Woodhead, N. E., Long, W. F. \& Williamson, F. B. (1986) Biochem. J. 237, 281-284 